\title{
Tumor de células gigantes tratado con translocación cubital y artrodesis de muñeca tras fracaso de curetaje y cementación
}

\section{Giant Cell Tumor of Distal Radius Treated with Ulnar Translocation and Wrist Arthrodesis after Failed Curettage and Cementation}

\author{
José Antonio Oteo $^{1}{ }^{10}$ Patricia Merino ${ }^{1}$ \\ ${ }^{1}$ Servicio de Cirugía Ortopédica y Traumatología, Hospital
Universitario de Fuenlabrada, Fuenlabrada, Madrid, Spain
}

Rev Iberam Cir Mano

\author{
Address for correspondence José Antonio Oteo, PhD, Servicio de \\ Cirugía Ortopédica y Traumatología, Hospital Universitario de \\ Fuenlabrada, Camino del Molino 2, Fuenlabrada, Madrid, 28942, Spain \\ (e-mail: oteom@yahoo.com).
}

\section{Resumen \\ Palabras clave \\ - tumor de células gigantes \\ - translocación cubital \\ - artrodesismuñeca}

El radio distal es la tercera localización en frecuencia para los tumores de células gigantes. El curetaje de la lesión más relleno de la misma con cemento, es una de las opciones de tratamiento. La cementación tras el curetaje puede tener complicaciones y obligar a la resección de la zona dañada. Presentamos el resultado de un caso, donde se hizo resección en bloque de la zona tumoral cementada más reconstrucción del área con translocación del cúbito y artrodesis de la muñeca. Es una técnica sencilla en la que se pierde movilidad, pero que consigue excelentes resultados clínicos y funcionales en mano y antebrazo.

The distal radius is the third most common site for giant cell tumors. Curettage and filled of void with bone cement is one of the treatment options. Cementation after curettage can have complications and can require resection of the damaged area. We report the outcome of one case, where we did en bloc excision of cemented tumor with translocation of ulna and wrist arthrodesis.It is a simple technique in which some mobility is lost, but achieving excellent clinical and functional results.

\section{Introducción}

El Tumor de células gigante (TCG) óseo es una neoplasia benigna localmente agresiva relativamente común, que se asocia con un gran espectro biológico que va desde una latencia benigna, hasta un potencial maligno altamente recurrente y en ocasiones metastásico.

El radio distal es su tercera localización en frecuencia. El diagnóstico es clínico y radiológico. Su tratamiento en el caso de no existir ruptura cortical es el curetaje de la lesión asociado con tratamientos coadyuvantes para reducir la tasa de recurrencias. Cuando existe daño en la cortical aunque sea mínimo, la mejor opción es la resección de la zona comprometida del radio y el relleno del defecto con aporte óseo.

\section{Caso Clínico}

Mujer de 63 años de edad, diestra y sin ninguna patología de interés, acudió a consulta por cuadro de dolor a nivel de muñeca izquierda sin antecedente traumático previo. En el estudio radiológico que se hizo, se observó una lesión lítica polilobulada localizada en radio distal, que parecía conservar la cortical aunque la expandiera ( $\mathbf{- F i g . ~ 1 ) . ~}$ received

October 23, 2018

accepted

September 3, 2019
DOI https://doi.org/

10.1055/s-0039-1698792. ISSN 1698-8396.
Copyright $\odot$ Thieme Revinter

Publicações Ltda, Rio de Janeiro, Brazil
License terms

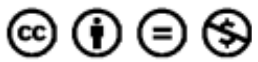




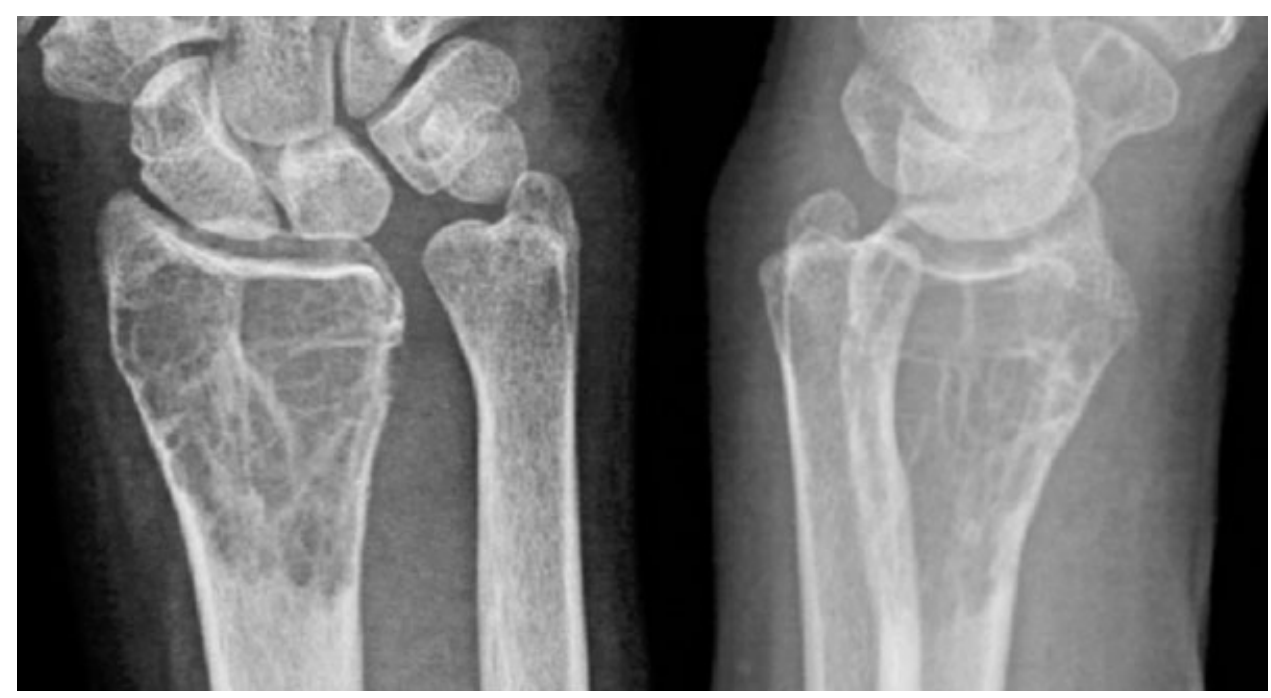

Fig. 1 Rx pre-quirúrgica

En la resonancia magnética (RM) con contraste de gadolinio realizada, se confirmó la lesión lítica en metáfisis y epífisis distal de radio, hipointensa en $\mathrm{T} 1$ y heterogénea con áreas hipointesas y otras tenuemente hiperintensas en STIR, de margen bien definido pero no escleroso que lindaba con la superficie articular, aunque con áreas de destrucción de la cortical y de inflamación de partes blandas adyacentes al hueso que sugerían una fractura patológica. Ante esos hallazgos, el principal diagnóstico era de TCG óseo, pero dada la edad de la paciente no podían desecharse otras posibilidades más agresivas como plasmocitoma o metástasis (- Fig. 2).

Para descartar esas patologías, se hizo una gammagrafía ósea (administración de 740 MBq de difosfonatos-Tc99m), existiendo sólo hipercaptación en la zona distal del radio izquierdo, presentando el resto del esqueleto una distribución regular del marcador ( - Fig. 3 )

Tras estas pruebas el caso fue presentado en el Comité de Sarcomas de nuestro Centro. Se prescribió la realización de una biopsia con aguja gruesa (BAG); la anatomía patológica mostró hallazgos citológicos encuadrables una neoplasia mesenquimal con componente de células gigantes de tipo osteoclásico.
Con el diagnóstico de TCG Campanacci grado II, se hizo en quirófano el curetaje de la lesión con cementación posterior de la cavidad (polimetilmetacrilato PMMA).

Tras la cirugía, la paciente inició un cuadro de dolor intenso en la muñeca asociado a limitación de la movilidad de la misma, con bloqueo en la pronosupinación. En la radiografía post-quirúrgica, se observaba relleno completo de la lesión con mínima salida de cemento por dorsal y volar, y deformidad de las dos superficies articulares del radio distal, en especial la radiocubital (-Fig. 4). Ante la persistencia de la clínica, se planteó hacer una nueva cirugía para retirar la zona dañada del radio; como el defecto resultante era muy grande y puesto que la paciente se negaba a que se le tomara injerto de peroné, se propuso hacer una translocación de cúbito a radio.

A través de una incisión dorsal, se resecó la porción distal del radio, que incluía la zona tumoral cementada más el margen de

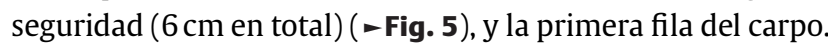
El tercio distal del cúbito se expuso manteniendo intacta la envoltura muscular y las estructuras neurovasculares. Se tomó un fragmento de cúbito distal de longitud igual al defecto dejado por los huesos resecados, y tras quitar la superficie articular distal del cúbito, se realizó la osteosíntesis empleando

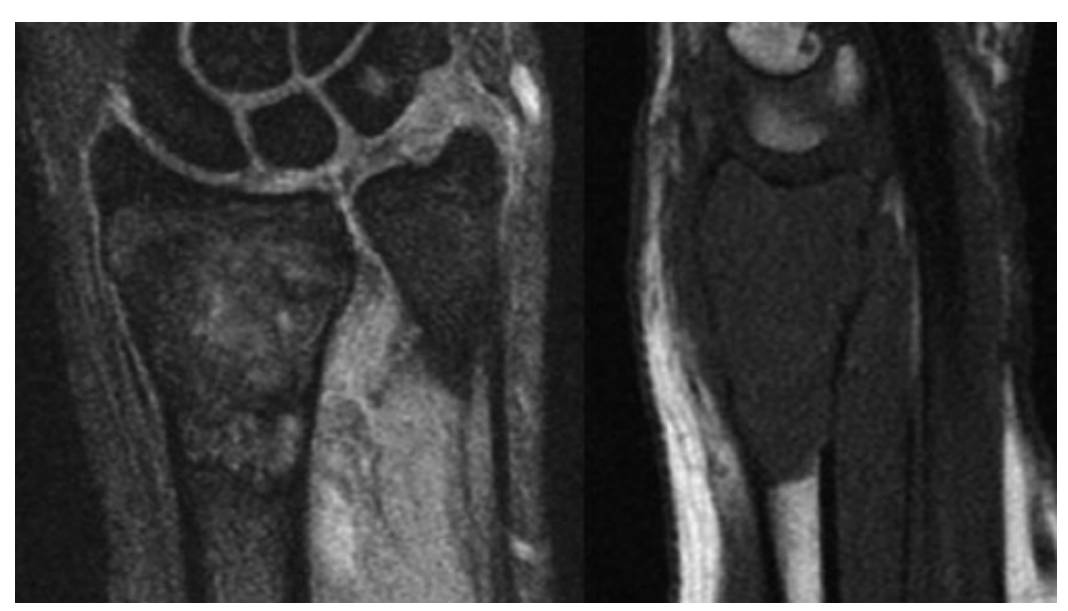

Fig. 2 RM pre-quirúrgica. 


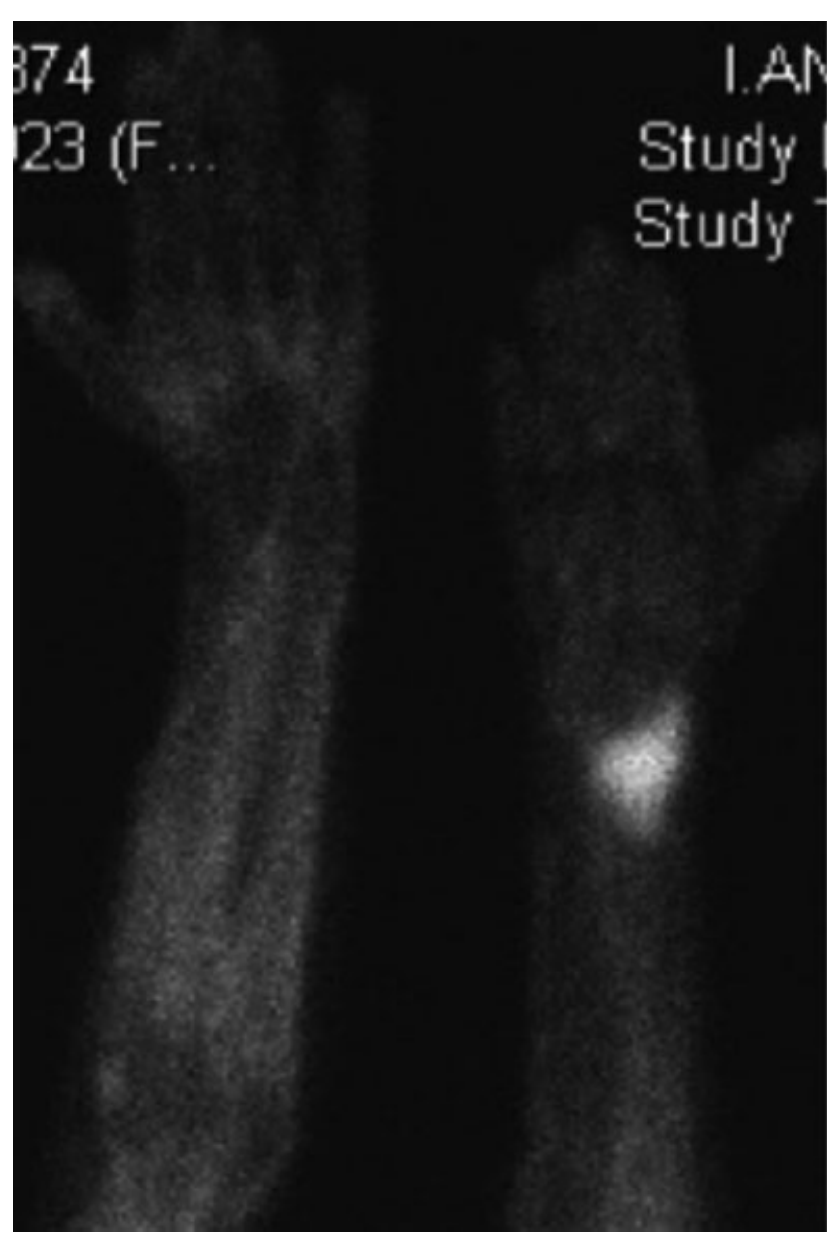

Fig. 3 Gammagrafía pre-quirúrgica

una placa LC-DCP de 14 agujeros con tornillos a tercer metacarpiano, colgajo óseo cubital y radio proximal. Tras la cirugía, se colocó una férula braquioantebraquial durante un mes, insistiendo en la movilización de los dedos. Pasado ese tiempo, se quitó la férula y se comenzó a mover el codo. A los cinco meses presentaba consolidación completa de la artrodesis (-Fig. 6).
Al año de evolución, la paciente no ha tenido recurrencia de la lesión, ni metástasis. Ha mejorado de forma significativa el cuadro de dolor (EVA ha pasado de 8 a 0 ), la funcionalidad de la mano (DASH ha cambiado de 84 a 20), la fuerza de puño (ha aumentado de $3 \mathrm{~kg}$ a $8 \mathrm{~kg}$ ) y ha recuperado la pronosupinación del antebrazo de forma parcial (tiene supinación completa, pero pronación sólo de 30) (Flg. 7). No ha presentado dolor a nivel del muñón distal del radio.

\section{Discusión}

El TCG es un tumor intramedular compuesto por células mononucleares y gigantes multinucleares, siendo esas últimas similares a los osteoclastos. ${ }^{1}$ Representa entre el $3 \%$ y el $8 \%$ del total de los tumores primarios óseos en la población occidental, mientras que ese porcentaje se eleva hasta el $20 \%$ en Asia oriental. ${ }^{1-3}$ El 80\% de las lesiones ocurren entre los 20 y 55 años. ${ }^{1}$ Tradicionalmente se ha considerado que son más frecuentes en mujeres pero hay también artículos que indican lo contrario. ${ }^{4}$ Se suelen localizar en la zona distal de huesos largos, especialmente en la rodilla (fémur distal y tibia proximal), siendo la extremidad distal del radio la tercera localización en frecuencia con un $10 \%$ de los casos. ${ }^{1,4,5}$ La recurrencia es variable situándose entre el 10\%-65\% de los casos, siendo más frecuente cuando el tumor invade las partes blandas. ${ }^{4,6}$ El 10\% malignizante teniendo entre el 1\%$4 \%$ de metástasis pulmonares. ${ }^{3,4}$ Los localizados a nivel de radio distal tienen más tendencia a la recurrencia local y a desarrollar metástasis. ${ }^{2,4,5}$

La clínica más habitual es el dolor local asociado con aumento de volumen e hipersensibilidad en la región afecta. Muchas veces, la forma de presentación es una fractura secundaria al adelgazamiento cortical ${ }^{1}$; esas fracturas son menos frecuentes en el radio distal que cuando la lesión está alrededor de la rodilla. ${ }^{4}$

La clasificación más usada es la de Campanacci, basada en su apariencia radiológica, que los divide en tres estadios, en el estadio I la lesión está bien definida con la cortical intacta, en el estadio II, el tumor expande la cortical pero no se extiende a los

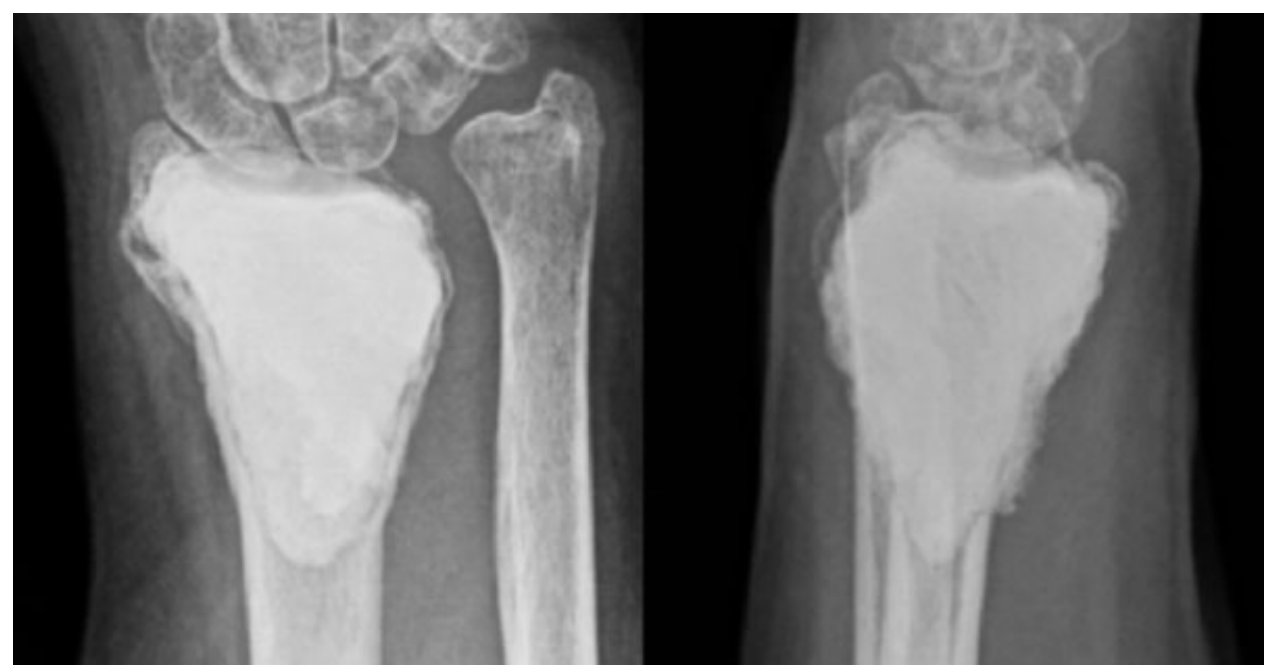

Fig. 4 Rx tras curetaje y cementado de la lesión. 


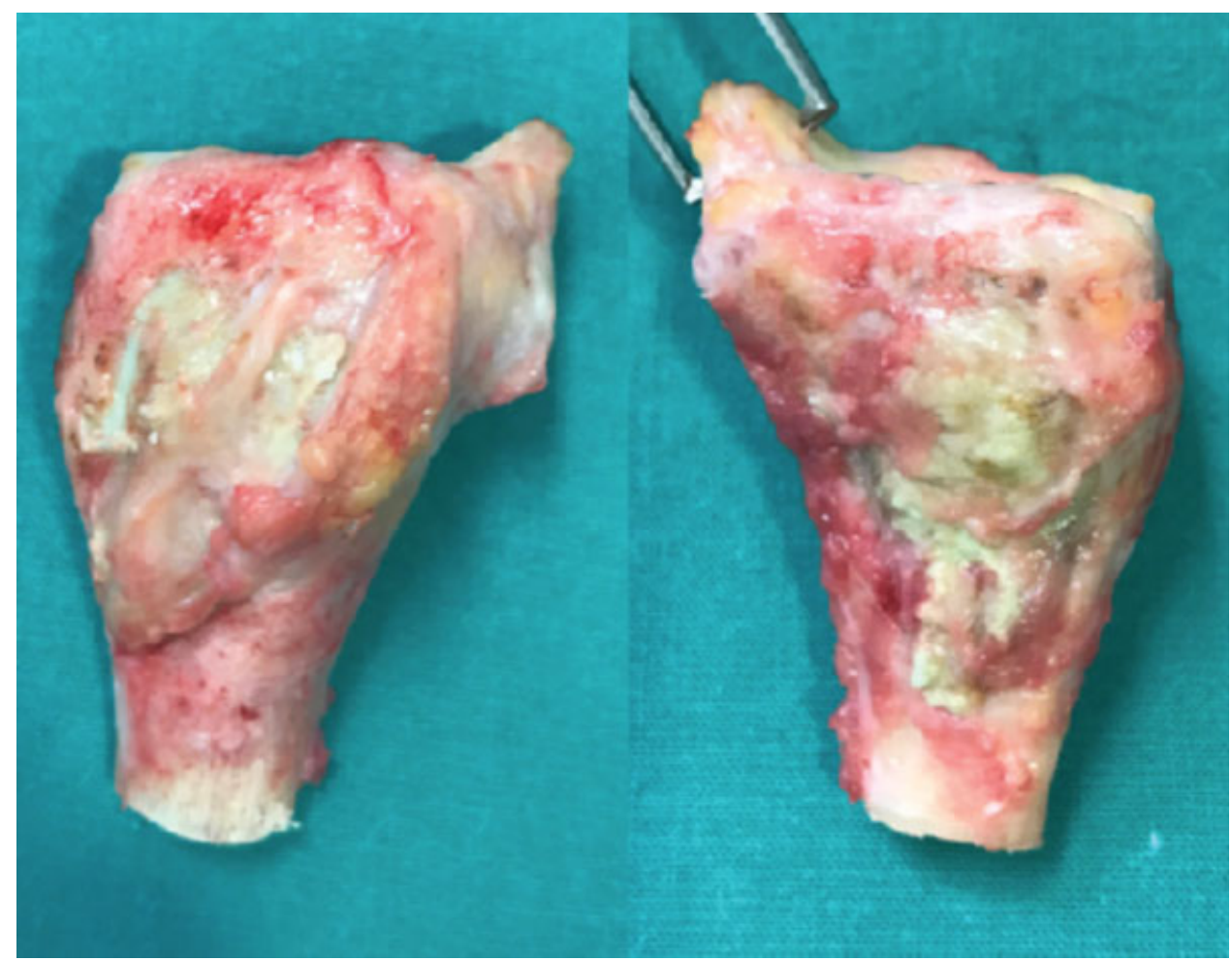

Fig. 5 Pieza quirúrgica.

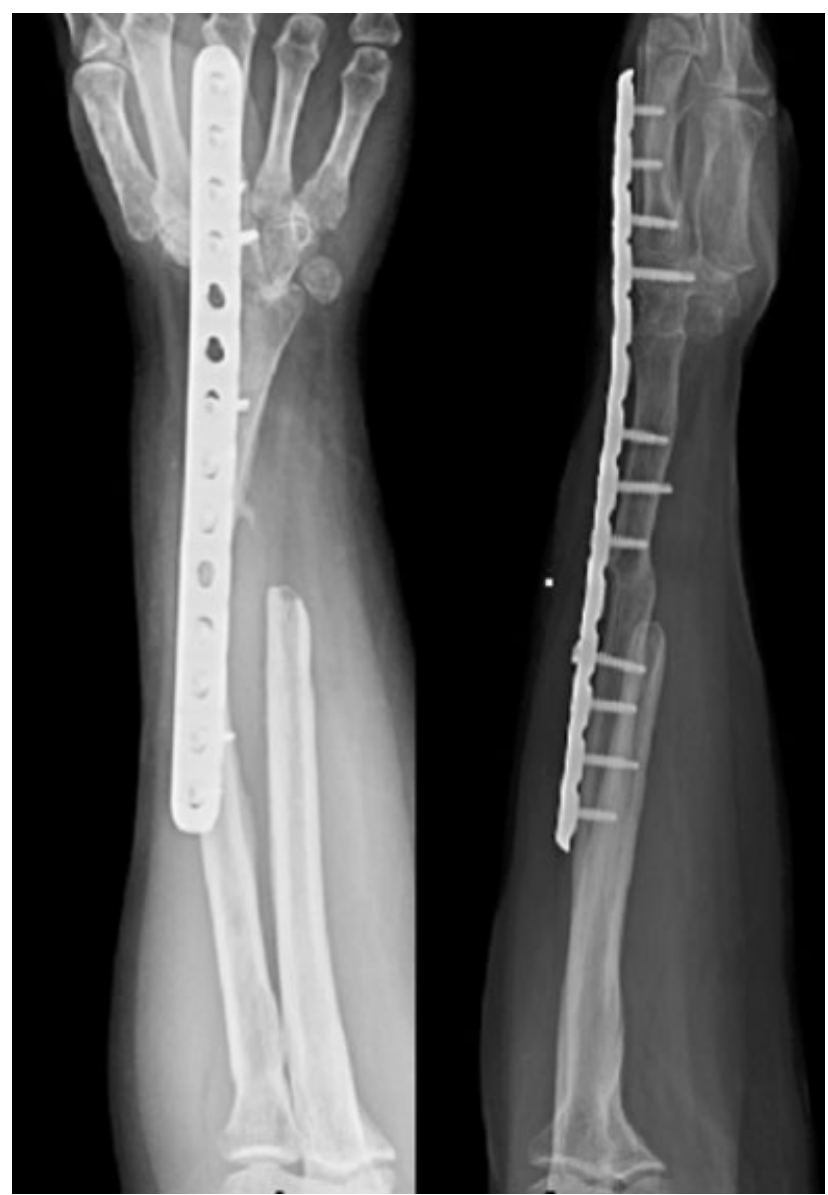

Fig. 6 Rx consolidación tras translación cubital y artrodesis de muñeca. tejidos blandos y el estadio III es cuando la lesión osteolítica penetra la cortical y se extiende a las partes blandas circundantes. ${ }^{1}$ Hay una mayor frecuencia de TCG estadio III en radio distal en comparación con otras localizaciones, posiblemente el retraso del diagnóstico al no tratarse de una articulación de carga sea responsable de ello. ${ }^{4}$

La radiografía simple y la resonancia magnética (RM) con contraste son las herramientas básicas para el diagnóstico del TCG. La tomografía computarizada (TC), puede ser utilizada para valorar el grosor cortical o la presencia de fracturas. La gammagrafía ósea añade poca información aunque ayuda a detectar múltiples focos, cuando se sospecha una enfermedad multicéntrica. 1

El diagnóstico actualmente se realiza con biopsia con aguja gruesa (BAG) guiada por ecografía o TC, reservándose la opción de biopsia abierta para cuando la cerrada no sea diagnóstica. ${ }^{1}$

Dos son básicamente las técnicas quirúrgicas que se utilizan en el tratamiento de esa patología, el curetaje de la lesión o la resección tumoral "en bloque". ${ }^{1}$ La recidiva de la enfermedad se asocia con el tipo de cirugía hecho, tras el curetaje la posibilidad de recurrencia es mayor (12-65\%) que después de la resección (0-16\%). Por lo general se aconseja el curetaje en los casos que conservan íntegra la cortical (Campanacci I) y la resección para aquellas lesiones con riesgo de extensión extraósea (Campanacci II y III) y en los casos de recurrencia, aunque siempre se debe individualizar el tratamiento según las características propias de cada tumor y paciente. ${ }^{1-4,6}$

El uso de denosumab en esa patología, puede favorecer el tratamiento, al disminuir el número y función de los osteoclastos y aumentar la masa ósea, y así conseguir 


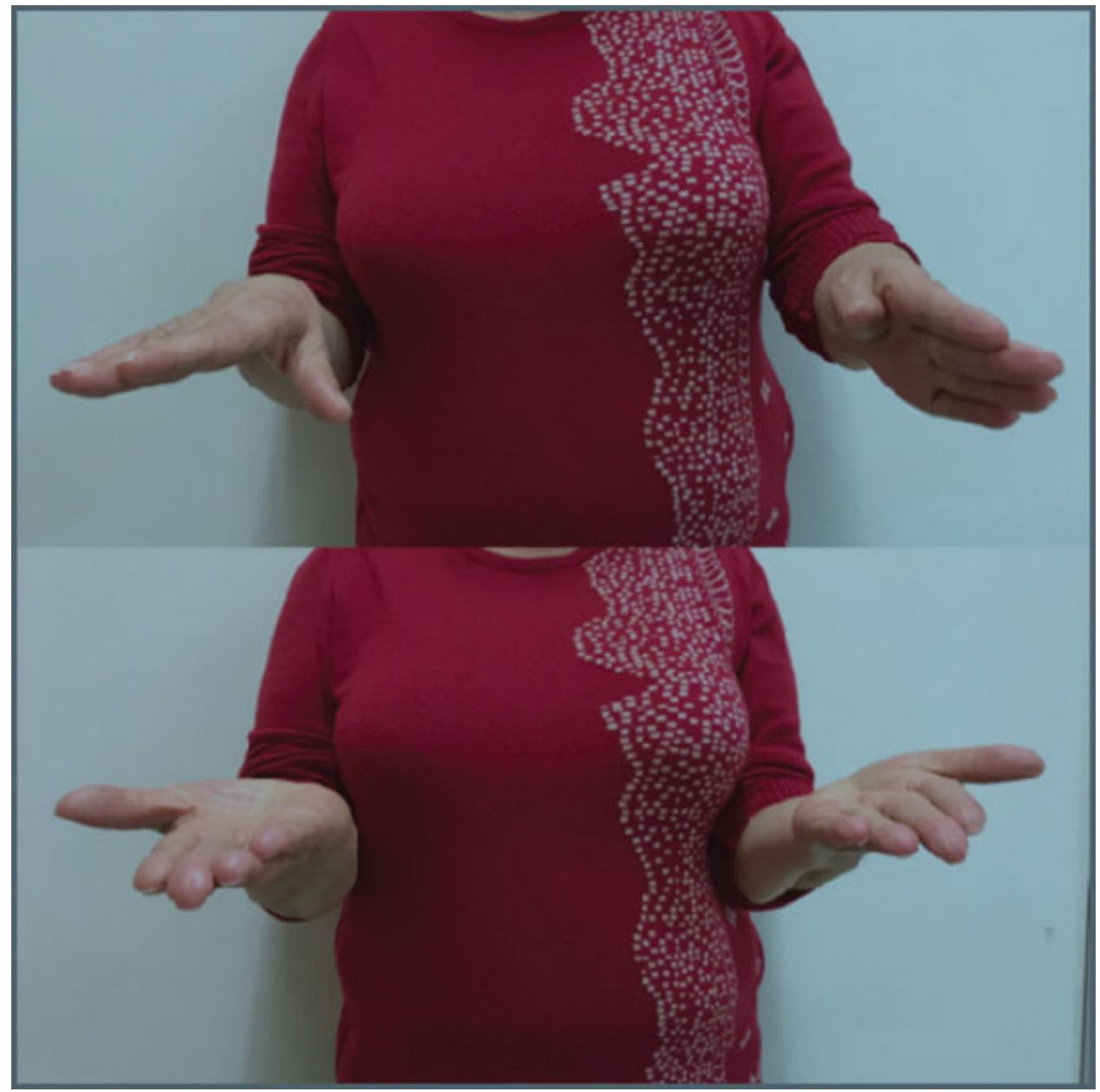

Fig. 7 Pronosupinación de antebrazo.

disminuir la magnitud de las lesiones. El mayor beneficio estaría en los casos con gran daño local, donde la cirugía se asocia con importante morbilidad. ${ }^{7}$ Cuanto mejor responda el tumor a la medicación, reduciendo su tamaño y aumentando la osificación, menor será la posibilidad de reaparición de la lesión. ${ }^{8}$ Pero no hay que olvidar que las células tumorales, pueden permanecer dentro del hueso neoformado, por lo que tras el tratamiento el realizar un curetaje puede aumentar el riesgo de recurrencia local, siendo preferible la resección. ${ }^{7}$

El curetaje puede hacerse sólo, pero para reducir las tasas de recidiva se han utilizado diferentes tipos de coadyuvantes solos o combinados, como fresado de alta velocidad, alcohol, fenol, peróxido de hidrógeno, cloruro de zinc, crioablación con nitrógeno líquido, aplicación local de ácido zolendrónico o cementación con polimetilmetacrilato (PMMA). ${ }^{1}$

El empleo de cemento tras el legrado del tumor provee de soporte mecánico inmediato al hueso lo que permite la movilización precoz. Debido a las altas temperaturas generadas durante la polimerización del PMMA, se asume que se eliminan las células tumorales residuales, reduciéndose las tasas de recurrencia (0-33\%). Sin embargo, eso puede generar necrosis en el cartílago y el hueso adyacente. ${ }^{9}$ Para evitar esa complicación han aparecido cementos que mezclan el PMMA con un material con cambio de fase (parafina), el cual hace que la temperatura se mantenga estable cuando se polimeriza el cemento, gracias a ello sin perder la biocompatibilidad, se consigue disminuir la necrosis térmica en el hueso vecino. ${ }^{10}$

Otros problemas vistos en relación con la cementación (13\%-25\%), incluyen la fuga del cemento a la articulación o a las partes blandas circundantes, y los cambios artrósicos de la articulación adyacente. $^{1}$

Para proporcionar soporte estructural tras el curetaje, sin el riesgo de necrosis avascular del cartílago articular y el hueso subcondral que puede hacer la cementación, se ha propuesto el revestimiento endóstico de la cavidad con un injerto microvascularizado de cresta iliaca. ${ }^{11}$

Si finalmente se opta por hacer la resección "en bloque" del radio distal afectado por un TCG, emplear injerto de peroné proximal no vascularizado para reconstruir el defecto, es la opción más utilizada. Esa intervención ocasiona un defecto en la zona dadora, requiere una inmovilización prolongada, y se ha ligado al fracaso en la consolidación y a la reabsorción del injerto. ${ }^{2}$ Para mejorar la consolidación ósea, el peroné también puede usarse como un colgajo vascularizado, pero eso prolonga el tiempo quirúrgico dado que hay que hacer microcirugía, además hay que contar con la variabilidad la arteria nutricia del peroné, que puede hacer que el injerto sea más largo de lo requerido, y tener cuidado al hacer la osteosíntesis para no dañar la vascularización del injerto. ${ }^{3} \mathrm{Si}$ se quiere evitar el daño en la zona dadora se puede emplear 
aloinjerto, pero es más caro y tiene alto riesgo de infección y de rechazo. ${ }^{3,5}$

El colocar la extremidad proximal del peroné como sustituta de la estiloides radial y de esa forma mantener la articulación de la muñeca, se ha asociado con luxación o subluxación del carpo así como con cambios degenerativos en la zona, por lo que la artrodesis se considera una mejor opción de tratamiento ${ }^{3,12}$

La reconstrucción del radio distal con cúbito distal (translocación cubital) es una intervención que no ocasiona morbilidad en otras extremidades, tiene un tiempo quirúrgico más corto que el injerto (vascularizado o no) de peroné, no requiere el empleo de técnica microquirúrgica, dado que la vascularización se mantiene debido a un manguito muscular que rodea al cúbito distal, funcionando como un colgajo vascularizado, mantiene en cierta medida la pronación y supinación conservando la función de la mano, y además gracias a que se asocia con artrodesis de muñeca, evita la luxación o subluxación del carpo. ${ }^{5}$ Se ha visto riesgo de no consolidación con esa técnica cuando se ha intentado una fijación intramedular con agujas. $^{3}$ La traslocación del cúbito cambia la forma de la muñeca, puesto que se estrecha y da un aspecto de reloj de arena a la zona. ${ }^{5}$

El principal riesgo al resecar el cubito distal es la impactación del muñón proximal del cúbito contra el radio al hacer fuerza o al cargar peso. Ese choque puede ser muy sintomático y obligar a realizar nuevas cirugías que incluyen desde el uso de una prótesis radiocubital distal, o la fusión de radio y cúbito para formar un antebrazo de hueso único. Pero no en todos los casos se ha visto esa complicación, hay estudios (mayoritariamente hechos en pacientes con lesiones tumorales), en los que una resección amplia del cúbito distal no ha ocasionado problemas de dolor posteriores, como ha sido en nuestro caso. Se ha propuesto que para mantener una estabilidad satisfactoria y no desarrollar dolor, el corte debe ser mayor del 25\% de la longitud del cúbito pero no superar el $45 \%$ de la misma, así se mantiene la banda central de la membrana interósea, que parece que es lo que da estabilidad al cúbito remanente. No se recomienda realizar esa técnica si la membrana interósea está dañada. ${ }^{13}$

En nuestro paciente, el curetaje del tumor más relleno con cemento no fue efectivo, el cemento deformó el hueso y salió fuera de sus límites, quizás porque ya había mínimas zonas de destrucción cortical, que se apreciaban en la RM. La traslocación cubital al radio tras la resección de la zona dañada, es una buena herramienta para conseguir que en un sólo acto quirúrgico mejore la función del antebrazo y la mano, aunque sea a costa de perder movilidad.

Conflictos de intereses. Ninguno

\section{BibliografíA}

1 Mavrogenis AF, Igoumenou VG, Megaloikonomos PD, Panagopoulos GN, Papagelopoulos PJ, Soucacos PN. Giant cell tumor of bone revisited. SICOT J 2017;3(54):54

2 Mozaffarian K, Modjallal M, Vosoughi AR. Treatment of giant cell tumor of distal radius with limited soft tissue invasion: Curettage and cementing versus wide excision. JOrthop Sci 2018;23(01): 174-179

3 Vyas A, Patni P, Saini N, Sharma R, Arora V, Gupta SP. Retrospective analysis of giant cell tumor lower end radius treated with En bloc excision and translocation of ulna. Indian J Orthop 2018;52(01): $10-14$

$4 \mathrm{Cao} \mathrm{H}$, Lin F, Hu Y, et al. Epidemiological and clinical features of primary giant cell tumors of de distal radium: a multicenter retrospective study in China. Sci Rep 2017;7(01):9067

5 Salunke AA, Shah J, Warikoo V, et al. Giant cell tumor of distal radius treated with ulnar translocation and wrist arthrodesis: What are the functional outcomes? J Orthop Surg (Hong Kong) 2017;25(01):1-6

6 Li D, Zhang J, Li Y, et al. Surgery methods and soft tissue extension are the potential risk factors of local recurrence in giant cell tumor of bone. World J Surg Oncol 2016;14:114

7 Abu-Zaid A, Alaqaili SI, Ahmad SO, Bin Hazzaa I, Alharbi H. Preoperative denosumab plus surgery in de management of giant cell tumor of bone: a comprehensive narrative literature review. Gulf J Oncolog 2019;1(30):67-75

8 Campanacci L, Sambri A, Medellin MR, Cimatti P, Errani C, Donati DM. A new computerized tomography classification to evaluate response to Denosumab in giant cell tumors in the extremities. Acta OrthopTraumatolTurc 2019:S1017-995X(18)30660-6

9 Ghouchani A, Rouhi G. The great need of a biomechanical-based approach for surgical methods of giant cell tumor: a critical review. J Med Biol Eng 2017;37(04):454-467

10 Lv Y, Li A, Zhou F, et al. A novel composite PMMA-bases bone cement with reduced potential for thermal necrosis. ACS Appl Mater Interfaces 2015;7(21):11280-11285

11 Sano K, Kimura K, Ozeki S. Vascularized iliac bone lining in downgraded treatment of Campanacci grade III giant cell tumor of the distal radius. JHand Surg Asian Pac Vol 2018;23(02): 255-258

12 Saikia KC, Borgohain M, Bhuyan SK, Goswami S, Bora A, Ahmed F. Resection-reconstruction arthroplasty for giant cell tumor of distal radius. Indian J Orthop 2010;44(03):327-332

13 Wolfe SW, Mih AD, Hotchkiss RN, Culp RW, Keifhaber TR, Nagle DJ. Wide excision of the distal ulna: a multicenter case study. J Hand Surg Am 1998;23(02):222-228 